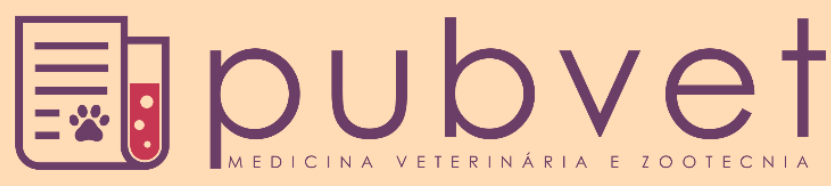

https://doi.org/10.31533/pubvet.v15n04a786.1-6

\title{
Avaliação in vitro da atividade hemolítica de isolados clínicos e ambientais de fungos dermatófitos
}

\author{
Clara de Almeida Mendes ${ }^{1} *{ }^{\bullet}$, Mário Mendes Bonci ${ }^{\circ}{ }^{\circ}$, Francisco de Assis Baroni $^{3}{ }^{\circ}$ \\ ${ }^{I}$ Mestranda no Programa de Pós Graduação em Medicina Veterinária da Universidade Federal Rural do Rio de Janeiro. Seropédica-RJ, Brasil. \\ ${ }^{2}$ Doutorando no Programa de Pós Graduação em Diagnóstico Bucal, Radiologia Odontológica e Imaginologia da Universidade de São Paulo. \\ São Paulo-SP, Brasil. \\ ${ }^{3}$ Professor da Universidade Federal Rural do Rio de Janeiro, Departamento de Microbiologia e Imunologia Veterinária. Seropédica - RJ, Brasil. \\ *Autor para correspondência,E-mail: claramendess@live.com
}

Resumo. Os dermatófitos são fungos queratinolíticos responsáveis pela dermatofitose, micose superficial zoonótica transmitida através do contato direto, raramente capaz de penetrar tecidos profundos de indivíduos imunocompetentes. Dentre os fatores de virulência dos dermatófitos estão enzimas extracelulares e fatores não-enzimáticos, como a produção de hemolisinas. Objetivou-se investigar a capacidade de produção in vitro de atividade hemolítica por dermatófitos, contribuindo para o estudo da patogênese da dermatofitose e para o desenvolvimento de terapias e estratégias profiláticas mais eficazes. Foram utilizadas 32 amostras dentre isolados clínicos e ambientais de fungos dermatófitos, sendo elas: Nannizzia gypsea, Nannizzia nana, Microsporum canis e Trichophyton spp. Os fungos trabalhados foram obtidos a partir de isolamento ambiental pela técnica de Vanbreuseghem e de casos clínicos por amostras encaminhadas ao Laboratório de Diagnóstico Microbiológico Veterinário da Universidade Federal Rural do Rio de Janeiro, sendo mantidos em meio seletivo para fungos patogênicos, incubados a $28^{\circ} \mathrm{C}$ por até 30 dias. O ensaio da produção de hemolisina foi realizado em placas com ágar base para sangue suplementado com $5 \%$ de sangue ovino. Após inoculação, as amostras foram incubadas a $25^{\circ} \mathrm{C}$ e, posteriormente, a $37^{\circ} \mathrm{C}$, sendo monitoradas diariamente. A atividade hemolítica foi verificada macroscopicamente na presença de uma zona transparente de degradação de substrato ao redor da colônia. A $25^{\circ} \mathrm{C}$, aproximadamente $78 \%$ das amostras apresentaram resultados positivos para atividade hemolítica, e $91 \%$ de amostras foram positivas quando se empregou a temperatura de $37^{\circ} \mathrm{C}$. As amostras de dermatófitos possuem capacidade de produção de hemolisinas in vitro, o que sugere a capacidade de diminuição da resposta imune celular dos hospedeiros. Sugere-se estudos in vivo para o melhor entendimento destes mecanismos.

Palavras chave: Dermatofitose, exoenzimas, geofílicos, hemolisina, imunidade

\section{In vitro evaluation of the hemolytic activity of clinical and environmental isolates from dermatophyte fungi}

Abstract. Dermatophytes are keratinolytic fungi responsible for dermatophytosis, a
zoonotic superficial mycosis transmitted through direct contact, rarely capable of
penetrating deep tissues of immunocompetent individuals. Among the virulence factors of
dermatophytes are extracellular enzymes and non-enzymatic factors, such as the production
of hemolysins. The objective was to investigate the in vitro capacity of hemolytic activity
production by dermatophytes, contributing to the study of the pathogenesis of
dermatophytosis and the development of more effective therapies and prophylactic
strategies. For the research 32 samples were used among clinical and environmental
isolates of dermatophyte fungi, namely: Nannizzia gypsea, Nannizia nana, Microsporum 
canis, and Trichophyton spp. Environmental fungi were isolated by Vanbreuseghem technique and clinicians from samples sent to the Veterinary Microbiological Diagnosis Laboratory of the Universidade Federal Rural do Rio de Janeiro, being kept in a selective agar for pathogenic fungi, incubated at $28^{\circ} \mathrm{C}$ for 30 days. The hemolysin production assay was performed on plates with agar supplemented with 5\% sheep blood. After inoculation, the samples were incubated at $25^{\circ} \mathrm{C}$ and, subsequently, at $37^{\circ} \mathrm{C}$, being monitored daily. Hemolytic activity was verified macroscopically in the presence of a translucent substrate degradation zone around the colony. At $25^{\circ} \mathrm{C}$, approximately $78 \%$ of the samples showed positive results for hemolytic activity, and $91 \%$ of samples were positive when the temperature of $37^{\circ} \mathrm{C}$. The dermatophyte samples have the capacity to produce hemolysins in vitro, which suggests the ability to decrease the cellular immune response of the hosts. In vivo studies are suggested to better understanding these mechanisms.

Keywords: Dermatophytosis, exoenzymes, geophilic, hemolysin, immunity

\section{Introdução}

Os dermatófitos são fungos queratinolíticos responsáveis pela micose superficial zoonótica denominada dermatofitose, acometendo até $25 \%$ da população mundial (Elavarashi et al., 2017) e com alta taxa de reinfecção (Aktas \& Yıııt, 2015). A dermatofitose é transmitida por contato direto e raramente penetra tecidos profundos de indivíduos imunocompetentes. Os gêneros envolvidos na infecção dermatofítica são: Microsporum spp., Trichophyton spp., Epidermothyton spp., Nannizzia spp., Lophophyton spp. e Arthroderma spp. (Begum et al., 2020).

Dentre os fatores de virulência dos dermatófitos, estão enzimas extracelulares e fatores nãoenzimáticos, como a produção de hemolisinas (Gnat et al., 2018, 2019; Ramos et al., 2020). As hemolisinas são exotoxinas de efeito citotóxico nas membranas dos eritrócitos e células fagocíticas, com capacidade de lisar os glóbulos vermelhos e liberar ferro, requerido no crescimento fúngico, contribuindo para a estratégia de sobrevivência durante infecções oportunistas (Aktas \& Yıgıt, 2015), sendo relatadas em fungos como Histoplasma capsulatum, Candida albicans, Malassezia spp., Paracoccidioides spp. e Cryptococcus neoformans (Cezar-dos-Santos et al., 2018; Mohammadi et al., 2020; Salvin, 1951; Tee et al., 2019).

Conjectura-se que as hemolisinas são importantes no equilíbrio entre a imunidade celular do hospedeiro e a capacidade do fungo em diminuir sua resposta (Gnat et al., 2018). Amplamente estudadas em bactérias, é importante ressaltar seu papel na patogênese de doenças infecciosas fúngicas, onde a perda de atividade enzimática pode resultar em avirulência (Döğen et al., 2015).

Objetivou-se investigar as atividades hemolíticas de dermatófitos isolados do solo e de animais sintomáticos, a fim de verificar a produção in vitro de hemólise e ampliar a compreensão sobre este fator de virulência na possível prevalência do patógeno no hospedeiro, contribuindo para o desenvolvimento de terapias e estratégias profiláticas mais eficazes.

\section{Material e métodos}

Foram utilizadas amostras clínicas e ambientais. As amostras clínicas foram obtidas a partir de animais com lesões dermatofíticas encaminhadas ao Laboratório de Diagnóstico Microbiológico Veterinário da Universidade Federal Rural do Rio de Janeiro, somando 19 isolados de fungos dermatófitos, sendo 4 isolados de Nannizzia gypsea, 12 de Trichophyton spp., 1 de Nannizzia nana e 2 de Microsporum canis. As amostras encaminhadas ao laboratório foram submetidas ao isolamento em meio seletivo e ao exame microscópico direto, feito com solução a $10 \%$ de $\mathrm{KOH}$, analisando-se a presença de artroconídios e outras estruturas fúngicas.

Para as amostras de solo, foram utilizados 13 isolados, sendo 12 Nannizzia gypsea e 1 Nannizzia nana. Estas amostras foram obtidas de localidades onde a presença de animais fosse evidente, como canis, currais, praças e parques. Os fungos foram isolados destas amostras seguindo a técnica proposta por Vanbreuseghem (1952), utilizando pelos de equinos estéreis como iscas (fonte de queratina) para os dermatófitos. A partir da confirmação da presença do fungo por esta técnica, uma pequena parcela 
colonial foi retirada para observação em microscopia e isolamento em meio seletivo para fungos patogênicos.

A identificação dos fungos foi realizada pela observação de características macroscópicas e microscópicas, como proposto por de Hoog et al. (2000, 2017). Os isolados fúngicos ambientais e clínicos foram mantidos em tubos com Ágar seletivo para fungos patogênicos (Selective Agar for Pathogenic Fungi, Merck $^{\circledR}$, Alemanha), incubados a $28^{\circ} \mathrm{C}$, por até 30 dias.

O ensaio da atividade hemolítica foi realizado em Ágar base para sangue (Columbia Ágar, BD ${ }^{\circledR}$, França) suplementado com 5\% de sangue ovino, depositados em placas de Petri (90x15mm) estéreis. Uma porção colhida em alça de $10 \mu \mathrm{L}$ de cada colônia foi depositada no centro das placas. Após inoculação das 32 amostras, as mesmas foram incubadas por 7 dias em condições aeróbicas a $25^{\circ} \mathrm{C}$ e, posteriormente, incubadas por mais 5 dias a $37^{\circ} \mathrm{C}$, sendo monitoradas diariamente. A atividade hemolítica foi verificada macroscopicamente, na presença de uma zona transparente de degradação de substrato ao redor da colônia.

\section{Resultados e discussão}

Após incubação a $25^{\circ} \mathrm{C}$ por sete dias, aproximadamente $78 \%$ das amostras apresentaram resultados positivos para atividade hemolítica, demonstrando halo decorrente de atividade hemolítica ao redor da colônia, bizonal ou não, especificadas na Tabela 1 .

Tabela 1. Descrição da presença de atividade hemolítica à $25^{\circ} \mathrm{C}$ por 7 dias nas diferentes espécies e gênero.

\begin{tabular}{lcc}
\hline Espécies/Gêneros & $\mathrm{n}$ & Hemólise $/ 25^{\circ} \mathrm{C}$ \\
\hline Nannizzia gypsea, ambientais & 13 & 13 \\
Nannizzia gypsea, clínicos & 3 & 3 \\
Nannizzia nana, ambiental & 1 & 0 \\
Nannizzia nana, clínico & 1 & 0 \\
Microsporum canis, clínicos & 2 & 0 \\
Trichophyton spp., clínicos & 12 & 9 \\
\hline
\end{tabular}

A partir do oitavo dia de incubação, já a $37^{\circ} \mathrm{C}$ (5 dias), obteve-se aproximadamente $91 \%$ de resultados positivos (Figura 1).

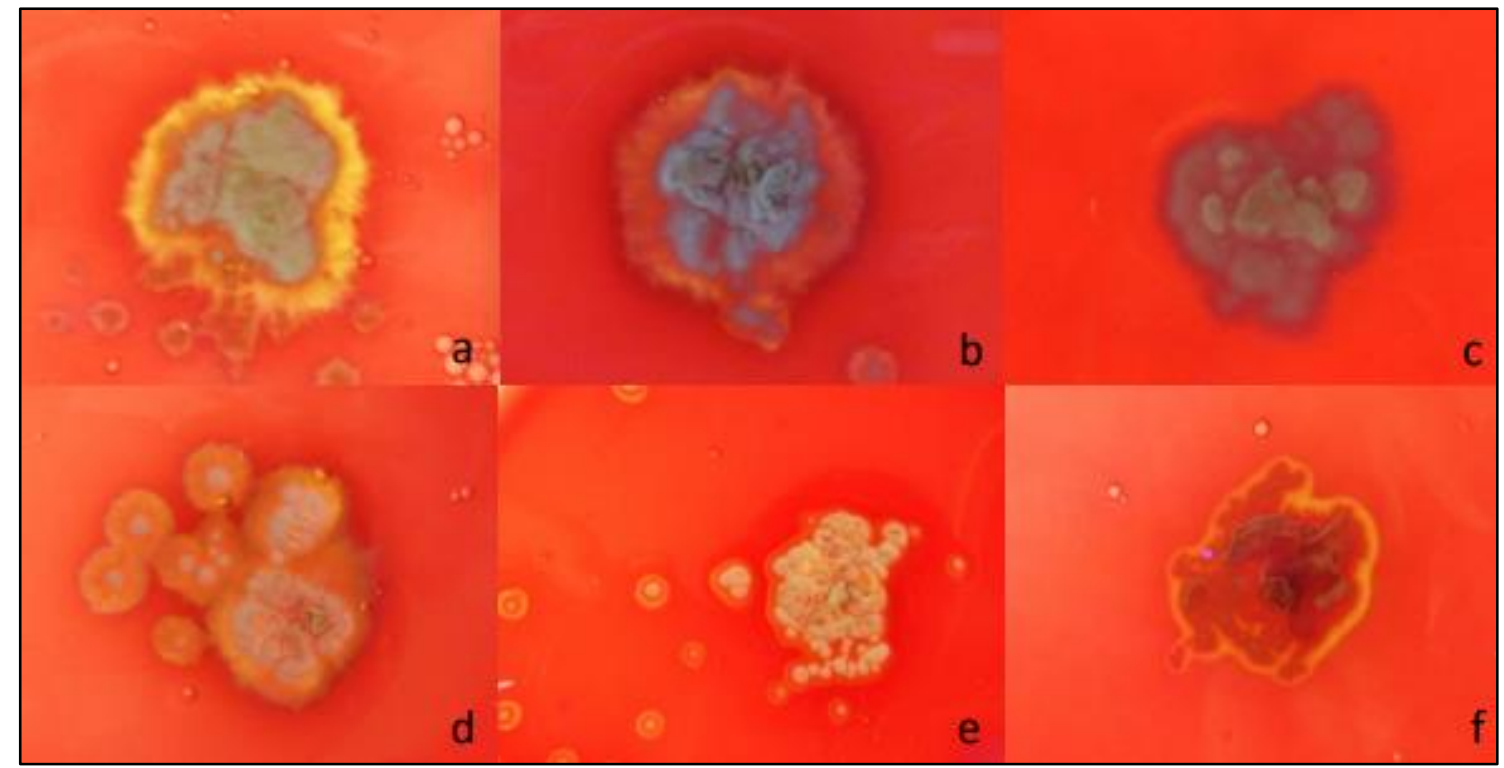

Figura 1. Colônias de dermatófitos com atividade hemolítica após 7 dias de incubação à $25^{\circ} \mathrm{C}$ em ágar sangue de ovino $5 \%$, (a e b). Colônia de dermatófito sem atividade hemolítica após 7 dias de incubação à $25^{\circ} \mathrm{C}$ em ágar sangue de ovino $5 \%$, (c). Colônia de dermatófitos com atividade hemolítica após 5 dias de incubação à $37^{\circ} \mathrm{C}$ em ágar sangue de ovino $5 \%$, (d, e e f). 
Além das produções de hemólise já verificadas, produziram hemólise nos meios de cultivo duas amostras antes negativas de Trichophyton spp. e as duas amostras de Nannizzia nana, mantendo-se negativas apenas as amostras de Microsporum canis e uma amostra de Trichophyton spp. (Tabela 2).

Tabela 2. Descrição da presença de atividade hemolítica à $37^{\circ} \mathrm{C}$ por 5 dias (após $25^{\circ} \mathrm{C} / 7$ dias) nas diferentes espécies e gênero.

\begin{tabular}{lcc}
\hline Espécies/Gêneros & $\mathrm{n}$ & Hemólise $/ 25^{\circ} \mathrm{C}$ \\
\hline Nannizzia gypsea, ambientais & 13 & 13 \\
Nannizzia gypsea, clínicos & 3 & 3 \\
Nannizzia nana, ambiental & 1 & 1 \\
Nannizzia nana, clínico & 1 & 1 \\
Microsporum canis, clínicos & 2 & 0 \\
Trichophyton spp., clínicos & 12 & 11 \\
\hline
\end{tabular}

Embora os estudos quanto à atividade hemolítica dermatofítica ainda sejam limitados e sua importância na patogênese não seja bem caracterizada, nos últimos anos o número de pesquisas abrangendo esta atividade enzimática aumentaram (Gnat et al., 2018). No presente trabalho, nota-se que a temperatura elevada, ou o maior tempo de incubação, podem estar relacionados à produção dos halos de hemólise, assim como relatado por Aktas \& Yigit (2015).

As amostras de Nannizzia gypsea, em sua totalidade, expressaram resultados positivos quanto a sua atividade hemolítica já a $25^{\circ} \mathrm{C}$, estando de acordo como descrito por Aktas \& Yigit (2015). Estes resultados mostram, in vitro, a forte tendência de produção de hemolisinas por esta espécie geofílica.

Outra espécie avaliada foi Nannizzia nana, que também demonstrou atividade positiva nos dois isolados, embora tenha sido evidenciada apenas a $37^{\circ} \mathrm{C}$, temperatura compatível ao organismo de muitos animais e dos humanos, sugerindo melhor ambiente para manifestação do fator de virulência. Porém, no maior estudo já feito para padronização da atividade hemolítica, por Gnat et al. (2018), com mais de 234 cepas, foi descrita a atividade hemolítica negativa de Nannizzia nana em sua totalidade. Estudos in vivo ainda são requeridos para comprovar real papel destas hemolisinas em infecções dermatofíticas por esta espécie.

Em estudo de Gnat et al. (2018) todas as cepas de M. canis apresentaram atividade hemolítica in vitro a partir isolados humanos, sugerindo uma maior afinidade com queratinócitos humanos. Esta teoria de afinidade por queratinócitos humanos foi descrita em trabalho anterior, quando todos os isolados de dermatófitos clínicos secretaram hemolisina num estudo com mais de 200 pacientes humanos com suspeita de dermatofitose (Pakshir et al., 2016). É possível que no presente trabalho os achados tenham sido negativos devido aos isolados em questão não se tratarem de humanos, e sim de animais domésticos. Porém, Aktas \& Yigit (2015) e Elavarashi et al. (2017) também não relataram atividade hemolítica para esta espécie, ainda que tenham utilizado amostras humanas. A produção de hemolisina para esta espécie, portanto, precisa ser melhor esclarecida e padronizada.

Schaufuss \& Steller (2003) descreveram diferentes padrões para o gênero Trichophyton spp., indicando secreção de dois fatores citolíticos diferentes. Foram verificadas zonas de hemólise completa seguida por halo de hemólise incompleta em Trichophyton rubrum e Trichophyton equinum, sendo distintas as espécies Trichophyton mentagrophytes e Trichophyton verrucosum, que por sua vez produziram apenas um halo com hemólise completa.

A falta de padrão nos resultados encontrados neste trabalho para o gênero Trichophyton spp. podem estar relacionadas ao fato de apresentarem diferentes atividades de hemólise dentro de suas espécies descritas anteriormente, não separadas no presente estudo, restrito à classificação em gênero.

Schaufuss et al. (2007) descreveram uma maior sensibilidade para a avaliação hemolítica em eritrócitos equinos na espécie Trichophyton mentagrophytes. Döğen et al. (2015) relataram uma hemólise melhor observada nos gêneros Microsporum spp. e Trichophyton spp. em Agar Columbia suplementado com eritrócitos ovinos.

A possível influência do sangue utilizado em meio sólido para as diferentes afinidades entre espécies do gênero Trichophyton spp. também pode justificar a falta de padronização de resultados encontrado, visto que utilizou-se apenas sangue ovino, seguindo as sugestões de Aktas \& Yı1t (2015), justificada 
pela quantidade de esfingomielina nos fosfolipídios da membrana dos eritrócitos ser maior em ovinos e bovinos do que em equinos, sendo $51 \%$ e $13,5 \%$, respectivamente, induzindo uma maior atividade hemolítica.

Outro fator que poderia influenciar, no caso dos isolados clínicos, seria a gravidade e cronicidade da dermatofitose como descrito por Gnat et al. (2018), que relataram a espécie Trichophyton verrucosum exibindo hemólise bizonal apenas em animais sintomáticos, sugerindo uma relação com a evolução da doença.

Este mesmo estudo de Gnat et al. (2018) sugeriu que a hemólise é mais comum em isolados clínicos de humanos e que a atividade hemolítica pode variar de acordo com os hospedeiros, as espécies dermatofíticas e o estado imunológico do hospedeiro. Isto contradiz o que foi descrito por Döğen et al. (2015) e Aktas \& Yıgit (2015), que sugeriram que as atividades hemolíticas não estariam correlacionadas com características ecológicas ou manifestações clínicas, após verificarem produção de hemólise igualmente em sintomáticos e assintomáticos, sendo necessários estudos mais abrangentes sobre o assunto.

\section{Conclusões}

Concluiu-se que os dermatófitos possuem capacidade de produção de hemolisinas in vitro, que sugere contribuição na diminuição da resposta imune celular dos hospedeiros em infecções dermatofíticas, sendo este fato possível perpetuante do crescimento fúngico, devendo ser considerado para escolha terapêutica e novas abordagens profiláticas.

Fatores como influência de hospedeiros, influência do sangue utilizado, relevância estatística e associação in vivo devem ser considerados em estudos futuros para uma melhor caracterização da patogênese dermatofítica.

\section{Referências}

Aktas, E., \& Y1git, N. (2015). Hemolytic activity of dermatophytes species isolated from clinical specimens. Journal de Mycologie Médicale, 25(1), e25-e30. https://doi.org/10.1016/j.mycmed.2014.10.014

Begum, J., Mir, N. A., Lingaraju, M. C., Buyamayum, B., \& Dev, K. (2020). Recent advances in the diagnosis of dermatophytosis. Journal of Basic Microbiology, 60(4), 293-303. https://doi.org/10.1002/jobm.201900675

Cezar-dos-Santos, F., Lenhard-Vidal, A., Assolini, J. P., Marquez, A. S., Ono, M. A., \& Itano, E. N. (2018). Paracoccidioides restrepiensis B339 (PS3) and P. lutzii LDR2 yeast cells and soluble components display in vitro hemolytic and hemagglutinating activities on human erythrocytes. Microbiology and Immunology, 62(7), 436-443. https://doi.org/https://doi.org/10.1111/13480421.12599

Döğen, A., Gümral, R., \& İlkit, M. (2015). Haemolytic and co-haemolytic (CAMP-like) activity in dermatophytes. Mycoses, 58(1), 40-47. https://doi.org/10.1111/myc.12269

Elavarashi, E., Kindo, A. J., \& Rangarajan, S. (2017). Enzymatic and Non-Enzymatic Virulence Activities of Dermatophytes on Solid Media. Journal of Clinical and Diagnostic Research: JCDR, 11(2), DC23-DC25. https://doi.org/10.7860/JCDR/2017/23147.9410

Gnat, S., Łagowski, D., Nowakiewicz, A., \& Zięba, P. (2018). Phenotypic characterization of enzymatic activity of clinical dermatophyte isolates from animals with and without skin lesions and humans. Journal of Applied Microbiology, 125(3), 700-709. https://doi.org/10.1111/jam.13921

Gnat, S., Nowakiewicz, A., Łagowski, D., \& Zięba, P. (2019). Host- and pathogen-dependent susceptibility and predisposition to dermatophytosis. Journal of Medical Microbiology, 68(6), 823836. https://doi.org/10.1099/jmm.0.000982

Hoog, G. S., Dukik, K., Monod, M., Packeu, A., Stubbe, D., Hendrickx, M., Kupsch, C., Stielow, J. B., Freeke, J., Göker, M., Rezaei-Matehkolaei, A., Mirhendi, H., \& Gräser, Y. (2017). Toward a Novel Multilocus Phylogenetic Taxonomy for the Dermatophytes. Mycopathologia, 182(1-2), 5-31. https://doi.org/10.1007/s11046-016-0073-9 
Hoog, G. S., Guarro, J., Gené, J., \& Figueras, M. J. (2000). Atlas of clinical fungi (Issue Ed. 2). Centraalbureau voor Schimmelcultures (CBS).

Mohammadi, F., Ghasemi, Z., Familsatarian, B., Salehi, E., Sharifynia, S., Barikani, A., Mirzadeh, M., \& Hosseini, M. A. (2020). Relationship between antifungal susceptibility profile and virulence factors in Candida albicans isolated from nail specimens. Revista Da Sociedade Brasileira de Medicina Tropical, 53. https://doi.org/10.1590/0037-8682-0214-2019

Pakshir, K., Mohamadi, T., Khodadadi, H., Motamedifar, M., Zomorodian, K., Alipour, S., \& Motamedi, M. (2016). Proteolytic activity and cooperative hemolytic effect of dermatophytes with different species of bacteria. Current Medical Mycology, 2(4), 9-14. https://doi.org/10.18869/acadpub.cmm.2.4.9

Ramos, M. L. M., Coelho, R. A., Brito-Santos, F., Guimarães, D., Premazzi, M., Zancopé-Oliveira, R. M., Pereira, S. A., Gremião, I. D. F., Orofino-Costa, R., Figueiredo-Carvalho, M. H. G., \& AlmeidaPaes, R. (2020). Comparative Analysis of Putative Virulence-Associated Factors of Microsporum canis Isolates from Human and Animal Patients. Mycopathologia, 185(4), 665-673. https://doi.org/10.1007/s11046-020-00470-9

Salvin, S. B. (1951). Hemolysin from the Yeastlike Phases of Some Pathogenic Fungi. Experimental Biology and Medicine, 76(4), 852-854. https://doi.org/10.3181/00379727-76-18653

Schaufuss, P., Müller, F., \& Valentin-Weigand, P. (2007). Isolation and characterization of a haemolysin from Trichophyton mentagrophytes. Veterinary Microbiology, 122(3-4), 342-349. https://doi.org/10.1016/j.vetmic.2007.01.022

Schaufuss, P., \& Steller, U. (2003). Haemolytic activities of Trichophyton species. Medical Mycology, 41(6), 511-516. https://doi.org/10.1080/1369378032000141462

Tee, C. B., Sei, Y., \& Kajiwara, S. (2019). Secreted Hydrolytic and Haemolytic Activities of Malassezia Clinical Strains. Mycopathologia, 184(2), 227-238. https://doi.org/10.1007/s11046-019-00330-1

Vanbreuseghem, R. (1952). Biological technique for isolating dermatophytes from soil. Annales de La Societe Belge de Medecine Tropicale (1920), 32(2), 173.

\section{Histórico do artigo:}

Recebido: 29 de setembro, 2020.

Aprovado: 23 de outubro, 2020.

Disponível online: 23 de fevereiro, 2021.
Licenciamento: Este artigoé publicado na modalidade Acesso Aberto sob a licença Creative Commons Atribuição 4.0 (CC-BY 4.0), a qual permite uso irrestrito, distribuição, reprodução em qualquer meio, desde que $\mathrm{o}$ autor $\mathrm{e}$ a fonte sejam devidamente creditados. 